\title{
Thermal Analysis of Thermal Spray Coated Gray Cast Iron Brake Rotor
}

\author{
${ }^{1}$ Ekrem Altuncu, ${ }^{2}$ Recep Akyüz,,${ }^{3}$ Ozan Demirdalmış, ${ }^{4}$ Bilgi Çengelli \\ ${ }^{*}$ Materials and Manufac. Tech. App.\& Research Center-SUMAR, Sakarya University of Applied Sciences, \\ Sakarya, Turkey \\ ${ }^{2}$ Centre of Research \& Development, TOFAS, Bursa, Turkey \\ ${ }^{3}$ Centre of Research \& Development, KALEBALATA, Kocaeli, Turkey \\ ${ }^{4}$ Bodycote-Istaş, Turkey
}

\begin{abstract}
Braking is a process which transform the kinetic energy of the rotor into heat energy. During the braking phase, the frictional heat generated at the interface rotor-pad can lead to high temperatures $\left(>600{ }^{\circ} \mathrm{C}\right)$. In long-term frequent use of braking, increased temperature causes disc distortions, heat cracks, and causes degradation of the pad material. This creates a risk in the reduction of rotor-pad interface friction and loss of brake performance under safe driving conditions. In this study, the thermal monitoring of the thermal spray coated rotor was investigated and the variation of the friction coefficient and wear related thickness were measured. In addition, changes in torque forces at increasing temperatures were also evaluated.
\end{abstract}

Key words: thermal spray, brake disc, friction, thermal analysis

\section{Introduction}

During the braking action, kinetic energy of the vehicle is converted into heat due to frictional contact between the pads and disc [1-4]. The heat dissipation from the front rotor brakes is about $70 \%$ of the total content of kinetic energy [1,2]. Prolonged and continuous braking results in loss of braking efficiency due to excessive temperature in contact area [3]. So it is important to understand the thermal performance of brake disc under thermal loaded conditions. The main problem regarding hard braking is very large amount of heat flux is generated within short amount of time which causes reduce in the coefficient of friction. The heat released during braking increases the temperature ranging from $300^{\circ} \mathrm{C}$ to $800^{\circ} \mathrm{C}$. The thermal conductivity of pad must be less than that of rotor as the heat dissipation is predominantly due to the plastic micro deformation generated due to the frictional force [1]. The high temperature effect not only affects the service life of the rotor, but also reduces the life of the pad. Therefore, there is a risk of faster rotor wear, loss of brake performance and safe driving. As a result of this situation, different surface treatment and coating technologies have emerged in order to protect the rotor against thermal effects, reduce wear loss and increase its life. With the effect of thermochemical heat treatments called FNC, hard phases can be formed on the surface, provided that the gray cast iron rotor surface is modified. Both the surface hardness of the disc and its wear resistance can be improved. This treatment is mainly used to improve wear and fatigue properties and to enhance corrosion resistance [5]. The main factors in increasing the intense interest in rotor coatings are: environmental regulations, the obligation to increase the life of the rotor, the demand for longer-lasting rotors, rotor weight *Corresponding author: Address: Faculty of Technolgy, Department of Metallurgy and Materials Engineering, Sakarya University of Applied Sciences, 54187, Sakarya TURKEY. E-mail address: altuncu@ subu.edu.tr, Phone: +902642660269 
reduction studies. The advantages provided by the development and widespread use of thermal spray technologies (APS, HVOF) in the automotive industry have emerged as a candidate coating method for disc coating [7]. The coating layer can be deposited in desired thicknesses by spraying the feed material in powder or wire form (metallic or ceramic based) on the substrate in droplets with high acceleration with a spray gun. With a wide range of coating feedstock materials and optimization of spray parameters, coating corrosion and wear resistance can be achieved. Thermal spray coating methods are suitable for robotic controlled external and internal surface coating applications and mass production. In industrial applications, coating method and material selection is very critical. Both investment costs and operating costs should be considered. When a comparative evaluation is made between brake rotor coating methods, atmospheric plasma spray (APS) stand out due to their superior cost-benefit advantages for gray cast iron rotors. Deposition efficiency during the coating process, low heat input to the substrate, high deposition rate, high melting ability are some of the advantages. Plasma spray is preferred especially for spraying oxidebased wear resistant coatings with high melting point such as alumina, titania and chromia. In this study, the variation of friction coefficient, torque force variation, thermal analysis of thermal spray coated discs and counter pad materials at different test temperatures were compared under dynamometer performance test and real road test conditions.

\section{Materials and Method}

Grey cast iron is the most widely used material for brake disc. GG20 material is preferred as ventilated brake disc material in Fiat series vehicles due to its techno-economic advantage, high castability and machinability properties. Noise, vibration damping and thermal conductivity are excellent at service temperatures. The microstructure of the matrix, in nucleus, is mostly ferritic with less than $10 \%$ of perlite in total (Fig 1.). Before the coating process, the rotor surface was roughened by sandblasting. The coating process was carried out with a plasma spray F4 gun with optimum parameters [8]. An alumina-titania-based powder material in a certain size range was used as the coating material, and the SEM image can be seen in the Figure 2. NiCr-based bond layer was sprayed on the substrate to increase the adhesion of the ceramic layer and to prevent thermal expansion mismatches. In order to examine the microstructure of the coating, examinations were made in the SE and BSE mode under the scanning electron microscope (SEM) after the metallographic preparation processes. The cross-sectional and upper surface SEM view of the coating is shown in the figure 3 .

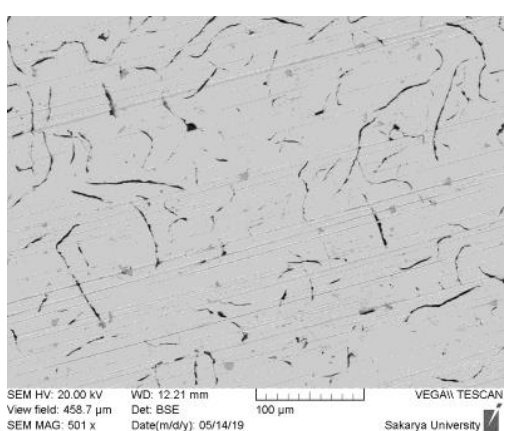

Figure 1. Microstructure of GG20

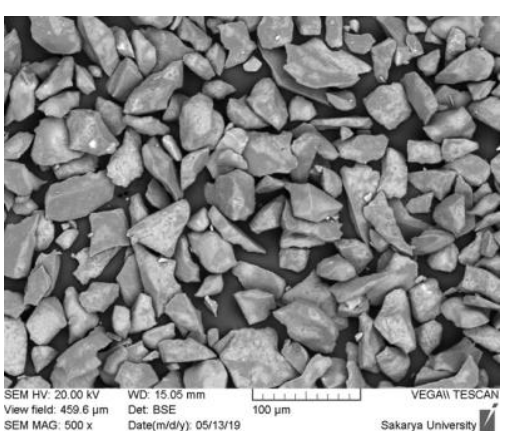

Figure 2. Powder feedstock material for APS 


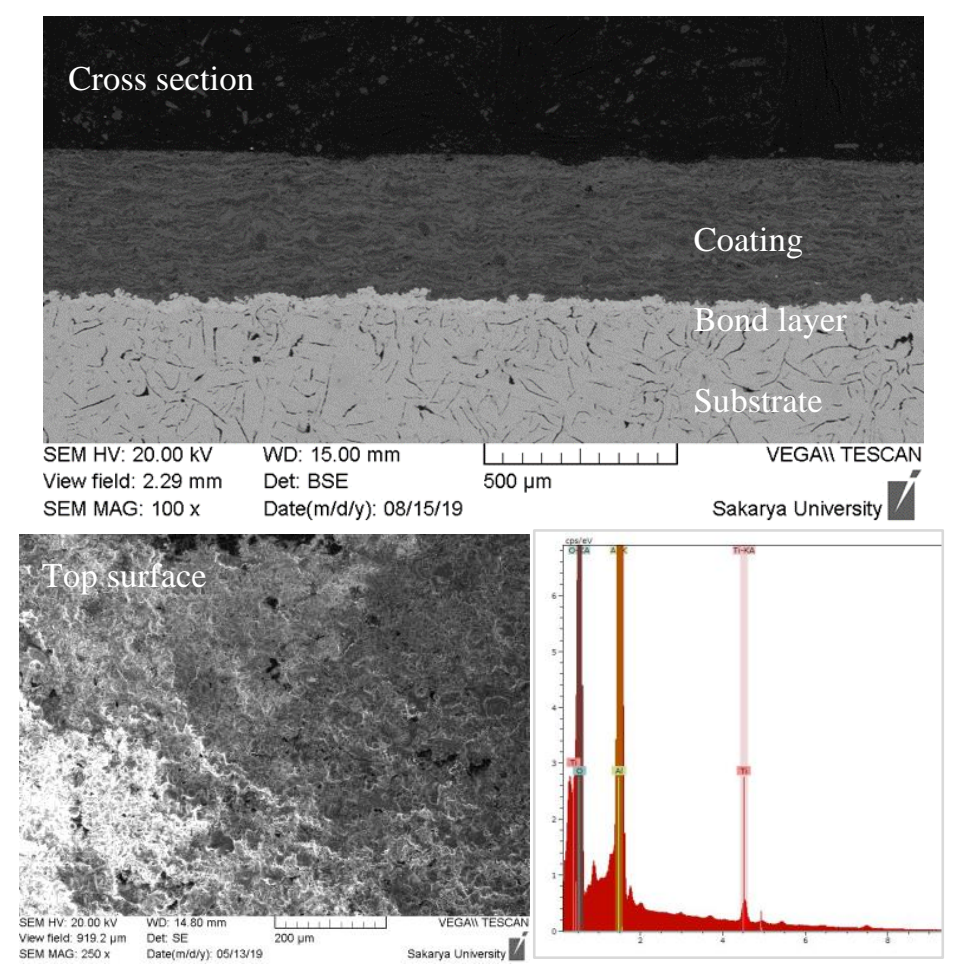

Figure.3 SEM views and EDX analysis of coating

Brake performance tests of coated rotors were carried out on dynamometer test bench (at Kale Balata Laboratory) at different test temperatures and with approximately 1000 brakes. In bench tests, temperature dependent rotor and pad wear were measured by section thickness variation. Afterwards, temperature measurements were monitored under real road conditions on the Uludağ climbing route. In order to monitor the temperature distribution on the disc, a thermocouple was attached to the inner and outer sections and the temperature changes depending on the braking number were monitored.

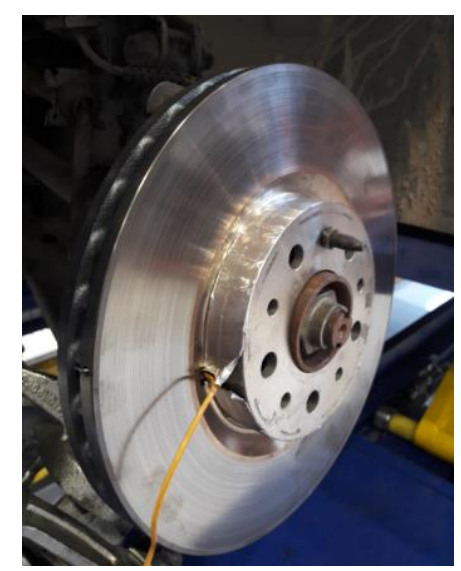

Figure 4. Temperature monitoring on rotor with thermocouple 


\section{Results and Discussions}

In figure 5, the wear graph of the rotor is displayed depending on the thickness change. The wear rate is highest in the uncoated rotor. If the wear-related thickness changes of the thermal spray coated and FNC treated rotors are compared, it can be seen that the wear loss of the plasma spray ceramic coated rotor is quite low. With the increase in temperature, the cross-section change is rapid and high in FNC-treated and uncoated rotors. In figure 6, the test results of the pad wear in contact with the rotor are displayed. Similarly, for uncoated discs, it is observed that the pad wear increases, and the thickness decreases with temperature. A significant degradation occurred on the pad surface in contact with the uncoated disc. It can be said that the coating has a reducing effect on both rotor and pad wear. This is very important in terms of long rotor life and international demands for brake dust reduction.

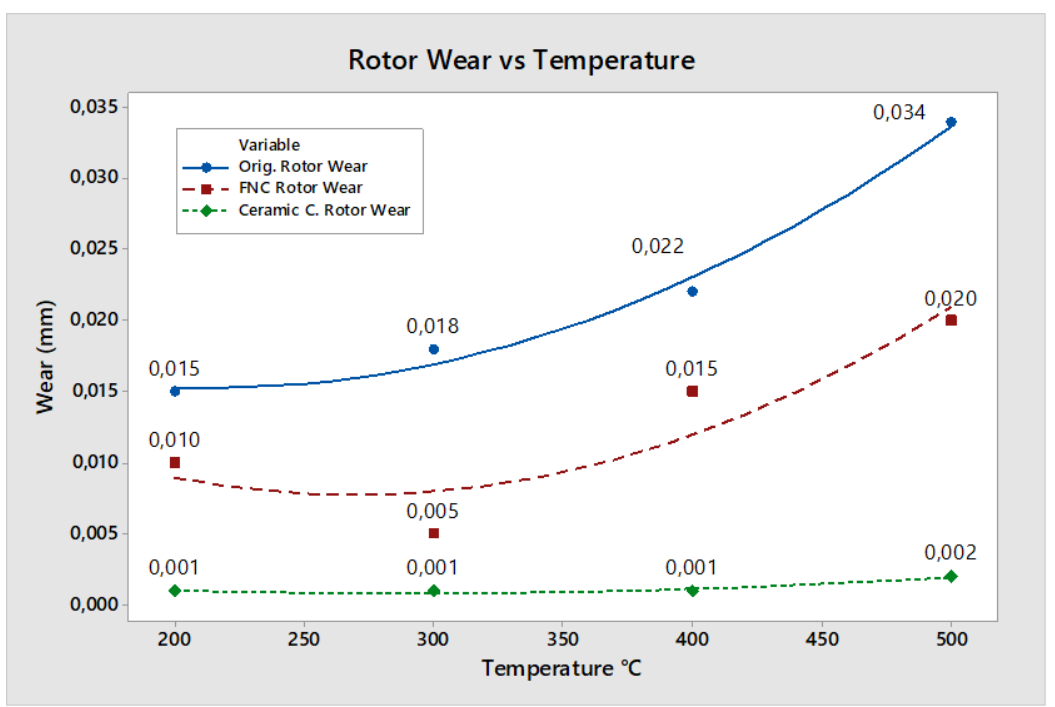

Figure 5. Wear plots for rotor at different test temperatures
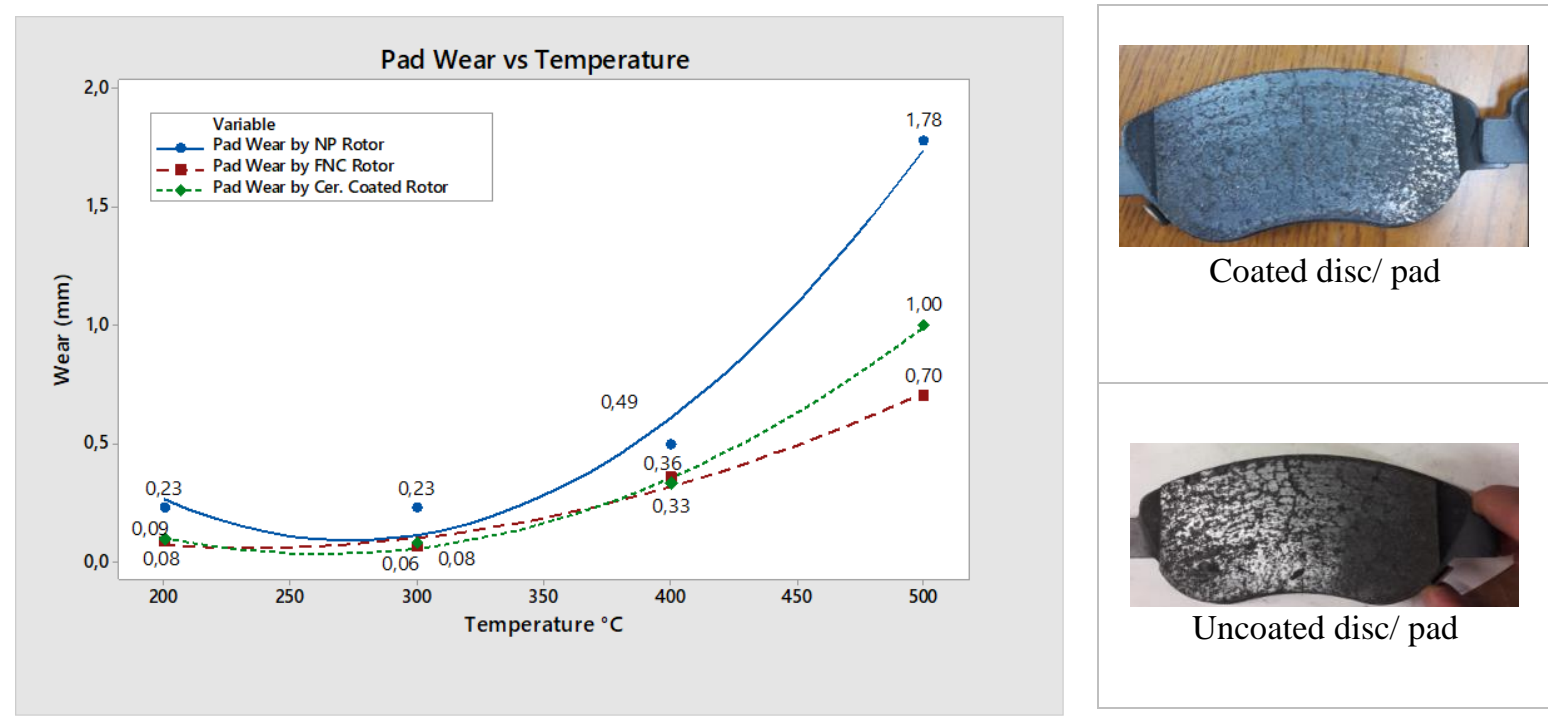

Figure 6. Wear plots for pads at different test temperatures and pad surfaces 
Brake torque is the force applied at the brake wheel to stop the motion of the moving equipment. The variation of braking torque was investigated depending on the temperature (Figure 7). As can be seen, it is observed that the torque force decreases with the coating processes. While the average torque forces are $1200 \mathrm{~N} / \mathrm{m}$ in the uncoated state, they decrease to relatively lower levels with the coating processes. The desired braking torque trend for the brake efficiency is that the torque curve should not fluctuate by increasing temperature. Therefore, the best result is obtained in the test with FNC implemented brake disc.

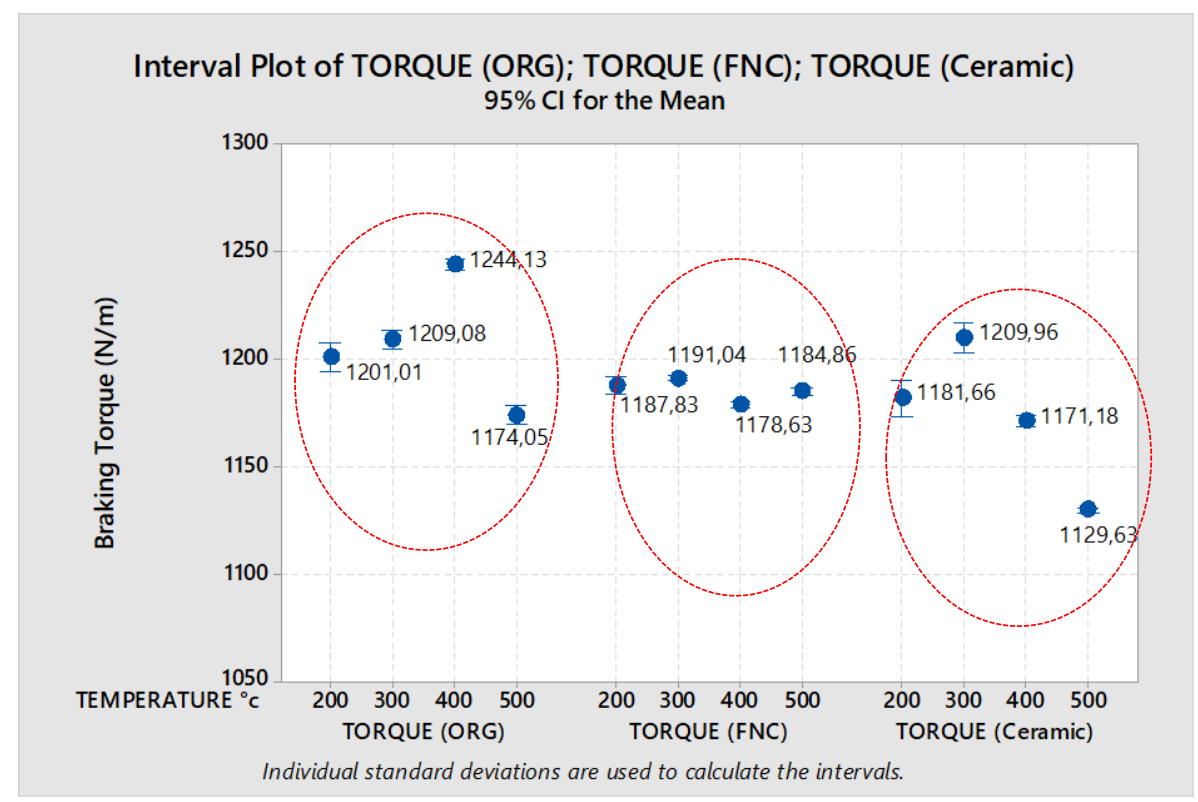

Figure 7. Torque variations of rotors at different test temperatures

In sudden braking conditions, temperatures increase suddenly. The thermal profiles of each sample were compared by a specially dedicated on-vehicle test (Figure 8-9). The test was performed according to the thermal performance of the customer usage profile standard. The test is consisting of ten successive brakes, then draws the cooling curves at a stable speed. The temperatures in the brake pads and on the brake disc surface were recorded instantly. After that, the thermal curves were created in the same test conditions. On the disc surfaces of the ceramic coated and uncoated rotors, the thermal curves are relatively aligned when compared to the curves in the pads. Also, the delta temperatures in the maximum temperatures are quite higher than the maximum temperature of the brake disc surfaces. The phenomena related to this situation can be barrier effect were created on the interface of the brake disc and pads by the ceramic coating. At this point, the heats which occurred by the friction during the brake application cannot be storage relatively effective in the brake rotors as compared to the condition of the uncoated brake disc. Therefore, the pads used with the ceramic coated disc are heating up more. This situation also reveals the need to develop pads with high thermal resistance and thermal stability. Otherwise, the weakening of the binder in the pad causes to wear very quickly. In the future, there will be the use of compatible coated disc-pad pairs. 


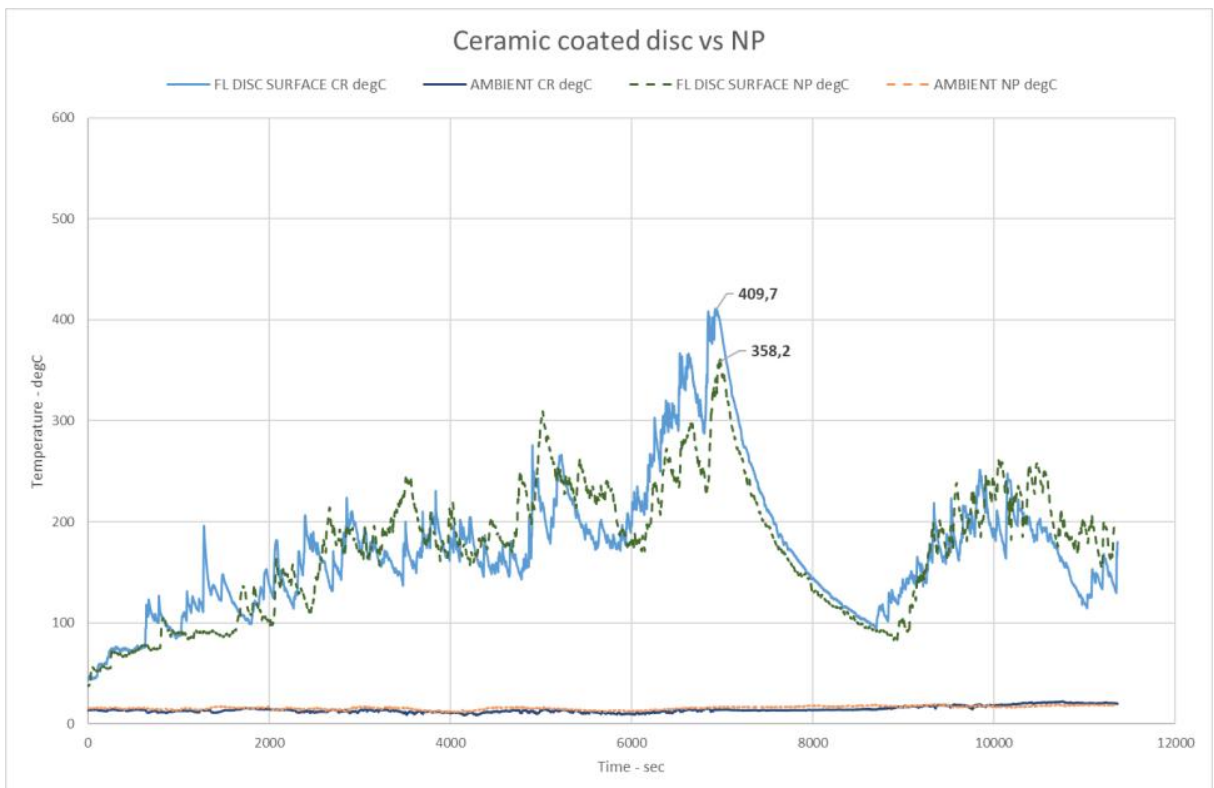

Figure 8. Temperature variation monitoring of rotor surface

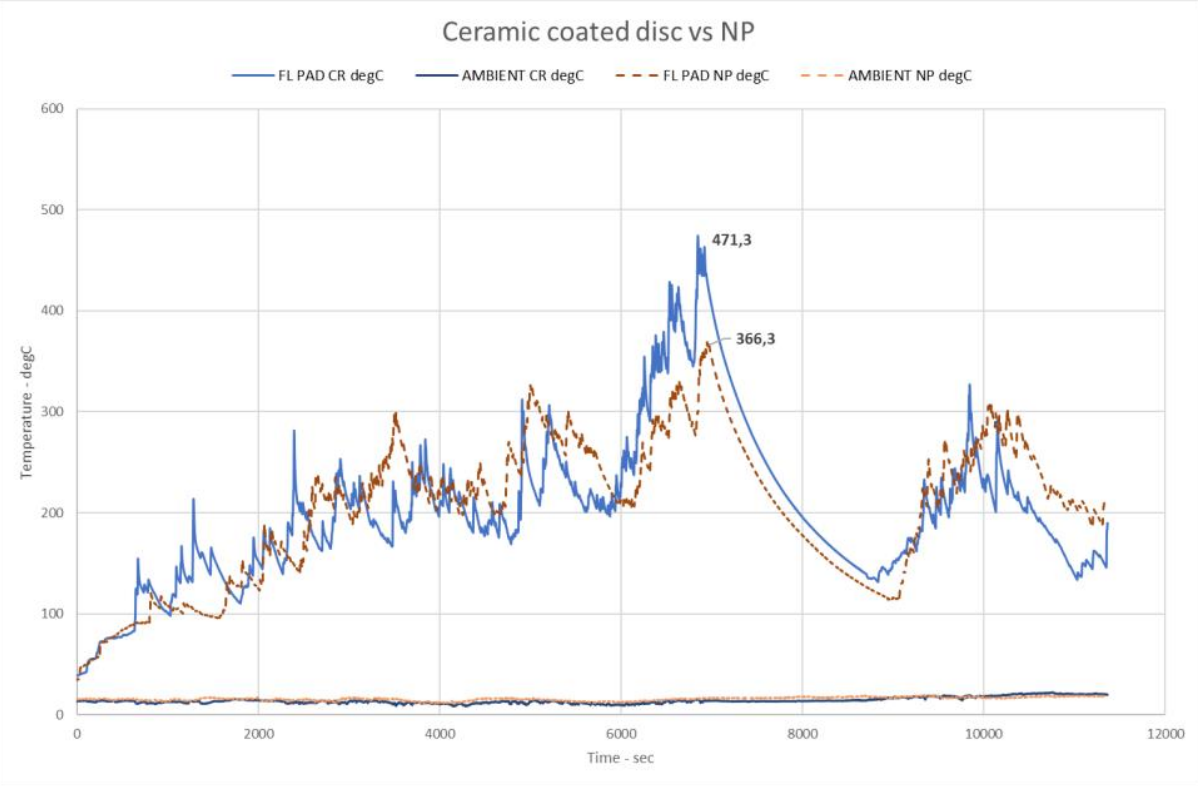

Figure 9. Temperature variation monitoring of pad

\section{Conclusions}

The increase in temperature due to friction in the brake rotor also increases the wear rate. There is a decrease in both pad and rotor thicknesses due to mass loss. FNC and plasma spray coating applications are successful in reducing wear and preventing rotor thickness variation. Alumina- 
Titania coating with plasma spray exhibits superior wear resistance even under increasing temperature conditions. Pad working with a coated rotor creates a more controlled wear than an uncoated rotor. Coating thickness is an important parameter in terms of heat transfer. In increasing coating thicknesses, the oxide-based coating reduces the heat dissipation and can act as a thermal barrier. This causes an increase in temperature between the rotor and pad. In our experimental studies, we succeeded in increasing the heat transfer by reducing the thickness as much as possible. Safe braking performance is ensured by controlling the change in friction coefficient due to temperature increase. The trend towards the combination of wear resistant, corrosion resistant disc coatings and pad materials with high thermal stability is increasing.

\section{Acknowlodgement}

In this study, the characterization of thermal spray coatings was carried out at Sakarya University. The authors thank TESLAB (Thermal Spray Tech. Lab.) directory and staff for their support.

\section{References}

[1] Belhocine A., Bouchetara M., Thermal analysis of a solid brake disc, Applied Thermal Engineering 32(1):2012, 59-67.

[2] Muthuvel, A., Prakash, N., \& Louis, S. W., Numérical analysis of a rotor disc for optimization of tire disc materials. J. of Mechanical Engineering and Automation, 5(3B ), (2015). 5-14.

[3] Talati, F., \& Jalalifar, S. (2009). Analysis of heat conduction in a disk brake system. Heat and Mass Transfer/Waerme-und Stoffuebertragung, 45(8), (2009), 1047-1059.

[4] Chavan C. B., Morea A. S., Patil N. N., Baskar P.b, Static structural and thermal analysis of brake disc with different cut patterns, J. Appl. Res. Technol vol.16 No.1 2018,41-52.

[5] Kim Y., Hong I., Study for Brake Friction Value and Anti Corrosion Performance by FNC Disc Compound Layer Thickness, Transactions of Korean Society of Automotive Engineers 27(5):2019, 399-404

[6] Aranke O., Algenaid W., Awe S., Joshi S., Coatings for Automotive Gray Cast Iron Brake Discs: A Review, Coatings 9, 552, 2019,1-27.

[7] Barbezat, G. Thermal spray coatings for tribological applications in the automotive industry. Adv. Eng. Mater. 8, 2006, 678-681.

[8] Altuncu E., Akyüz R., Applicability investigation of alumina-titania based plasma spray coating on cast iron brake discs for battery electric vehicles, Res. Eng. Struct. Mat. Vol. 6 Iss. 3 (2020) 283-292. 